\title{
Spomenik žrtvam vseh vojn in problematike sodobnega postavljanja javnih skulptur in spomenikov v Sloveniji
}

\section{IZVLEČEK}

Besedilo obravnava nekatere sodobne problematike postavljanja javnih skulptur in spomenikov v Sloveniji. Osredotoča se na Spomenik žrtvam vseh vojn, ki je bil poleti 2017 odkrit v središču Ljubljane. Spomenik in dogajanje okoli njega zajame kot primer zapleta, $v$ katerem neustrezno ravnanje različnih deležnikov $v$ dolgotrajnem procesu nastajanja spomenika proizvaja številna družbena nesoglasja in na koncu tudi problematičen spomenik.

Članek problematizira historični revizionizem v odnosu do druge svetovne vojne, ki se udejanja $v$ spomeniku in skozi procese, povezane $z$ njim. Preizprašuje, kako in zakaj nastane takšen velik državni spomenik, čeprav ni strokovno utemeljenega konsenza o tem, da spomeniki dejansko delujejo zdravilno na travmatizirane in postkonfliktne družbe, kot tudi ni konsenza o tem, da Slovenci v tem trenutku smo takšna družba. O spomeniku se pogosto govori kot o spomeniku spravi, čeprav ni konsenza o nujnosti sprave, kaj šele o tem, kaj naj bi ta sprava dejansko pomenila in kaj naj bi bili njeni elementi.

Ključne besede: Spomenik žrtvam vseh vojn, javna plastika, umetnost in družbena odgovornost, zgodovinski revizionizem, kolektivni spomin 


\section{ABSTRACT}

\section{THE MONUMENT TO THE VICTIMS OF ALL WARS AND THE ISSUES OF CONTEMPORARY PUBLIC SCULPTURES AND MONUMENTS IN SLOVENIA}

The text discusses some of the contemporary issues of erecting public sculptures and monuments in Slovenia. It focuses on the Monument to the Victims of All Wars, unveiled in the centre of Ljubljana in the summer of 2017. The monument and the events surrounding it are presented as an example of a predicament in which the inappropriate behaviour of the different stakeholders in the long-term process of monument creation produces numerous social disagreements and ultimately results in a problematic monument.

The article problematises the historical revisionism regarding World War II, which manifests itself in the monument and through the processes associated with it. It examines how and why such a large state monument can be created regardless of the absence of a professional consensus that monuments actually have a therapeutic effect on traumatised and post-conflict societies. Furthermore, there is also no consensus that Slovenians are currently such a society at all. The monument is often referred to as a tribute to reconciliation, although there is also no consensus about the necessity for reconciliation, let alone about what such reconciliation may actually mean and what its elements should be.

Keywords: Monument to the Victims of All Wars, public sculpture, art and social responsibility, historical revisionism, collective memory

Članek obravnava nekatere sodobne problematike postavljanja javnih skulptur in spomenikov pri nas. Osredotoča se na Spomenik žrtvam vseh vojn (odslej SŽV), ki je bil poleti 2017 odkrit v središču Ljubljane. Spomenik in dogajanje okoli njega zajame kot primer zapleta, v katerem neustrezno ravnanje različnih deležnikov $v$ dolgotrajnem procesu nastajanja spomenika proizvaja številna družbena nesoglasja in na koncu tudi problematičen spomenik. Članek opredeli in analizira najbolj problematične točke na poti nastanka spomenika in razmišlja o tem, kako ta organizira naš skupni prostor ter kaj s svojo konkretno formo govori.

Besedilo je bilo sprva pisano z opombami, vendar je bilo zavoljo aktualnosti vsebine tudi za širšo javnost najprej objavljeno brez njih v Sobotni prilogi časopisa Delo. ${ }^{1}$ Ponatisnjeno je izvorno besedilo, kakršno je bilo objavljeno v Delu, in zato govori o postavitvi spomenika v prihodnjiku. Opombe, ki so tokrat objavljene prvič, pa so malenkost posodobljene, tako da so vključeni nekateri dogodki in odzivi, povezani s spomenikom do poletja 2019. ${ }^{2}$

1 Beti Žerovc, »Spomenik, ki bo zapičen v naše osrčje za vselej, « Delo, 17. 3. 2017, pridobljeno 19. 1. 2019, https:// www.delo.si/sobotna/spomenik-ki-bo-zapicen-v-nase-osrcje-za-vselej.html.

$2 \mathrm{~V}$ opombah poskušam predvsem bolje pojasniti, kako je umetnostno polje $-\mathrm{s}$ tem mislim likovno in arhitekturno

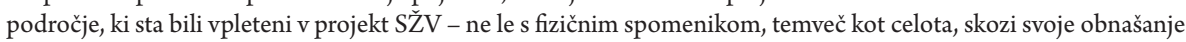


Henri Lefebvre, znameniti mislec prostora, je leta $1985 \mathrm{v}$ predgovoru knjige Produkcija prostora zapisal, da produkcijski način ureja - proizvaja - svoj prostor (in svoj čas) in se na ta način dovrši. ${ }^{3}$ Trditvi zlahka pritrdimo, sliši se logično, vendar kaj pravzaprav pomeni? Kaj bi to lahko pomenilo v primeru slovenskih mest?

Tukaj si verjetno na hitro zamislimo sebe kot sodobnega potrošnika $\mathrm{v}$ trgovskem središču na obrobju mesta - in samoobtožujoče zavzdihnemo. Morda večina ne razmišlja naprej o izčrpavanju meščanskih vsebin iz starih mestnih jeder in njihovi transformaciji za turistične namene, saj fasade ostajajo (bolj ali manj) iste. Še manj premišljujemo tako o novodobni produkciji javnih skulptur in spomenikov. Koliko sploh razmišljamo o svojem javnem prostoru kot o proizvedenem? O tem, kaj in kako ta komunicira z nami in kako sooblikuje naš (osebni) čas?

\section{Zakaj spomenik? Zakaj pa ne?}

Problematika postavljanja javnih skulptur in spomenikov je tako široka, da jo je težko zares zaobjeti in je naporna tudi za vse aktivno vpletene. Politik ali uradnik recimo ne vesta dovolj o umetnosti, arhitekt ali umetnik ne dovolj o politiki in zgodovini, zgodovinar ne ve dovolj o psihologiji spominjanja in komemoriranja, umetnostni zgodovinar spet ne o politiki in tako naprej. Resen diskurz o teh temah morda tudi zato pri nas pogosto izostane, kar je v neugodni korelaciji z opazno rastjo tovrstne produkcije. Postavljanje spomenikov in javnih skulptur je vse bolj razumljeno tudi kot zelo lokalna zadeva, in čeprav so postopki običajno vodeni zelo legalistično in so objekti občasno izbrani z natečaji, se dogaja tudi izrazita lokalizacija izvajalcev. Ti nemalokrat projekte tudi sami iniciirajo.

Vsebinsko so nove javne skulpture večkrat precej podobno prazne; v neke splošne obrazce vpisujemo redko dovolj premišljene lokalne ali nacionalne vsebine in (pol) resnice. Vprašanju, zakaj spomenik, je zadosten odgovor, zakaj pa ne. Odgovor, da

in odnos do tega velikega državnega naročila sodelovalo v vzpostavljanju nekakšne nove, širše sprejemljivejše oblike revizionizma v odnosu do druge svetovne vojne, ki se sicer glasno ne opredeljuje za eno ali drugo stran, se pa združuje v poziciji, da so bili »itak vsi isti «.

Na začetku poudarjam, da je spomenik lahko učinkovit instrument za politično polarizacijo znotraj skupnosti (op. 5). Srž konkretnega problema razlagam skozi dva povezana aspekta. Prvi je nejasen status umetnikov, ki slednjim omogoča, da se zlahka in, zdi se, brez posebnega razmišljanja o odgovornosti premeščajo od pragmatičnega obrtnika do globoko intuitivnega in etičnega ustvarjalca, pri čemer pa jih družba precej stabilno dojema v drugi poziciji in jim tudi naloge in bonitete določa v skladu s tem (op. 4, 10). Drugi je skrajna nejasnost pojmovnega okvira konkretnega spomenika (op. 11), kjer v procesu nastajanja spomenika nekako ni bilo čisto jasno, kaj se postavlja (toliko manj, ker je projekt, ki ga je priklicovala desnica, na koncu rade volje izvedla politična leva sredina s predsednikom Pahorjem na čelu). To dvoje skupaj je lahko ustvarilo dovolj »megleno situacijo «, da v umetnostnem polju, kljub nelagodju, ni prišlo do artikuliranega nesodelovanja ali obstrukcije projekta niti do refleksije vloge in odgovornosti umetnika (oziroma širše - umetnostnega protagonista) ter potencialne škodljivosti njegovih dejanj.

Henri Lefebvre, Produkcija prostora (Ljubljana: Studia Humanitatis 2013), 13. 
imajo podobne reči drugod po Evropi, pa tako ali tako zapre vsaka sitna usta. O dejanskih učinkih takšnih objektov se le malo pogovarjamo, kar pogosto je mnenje, da so te stvari bolj za turiste. Javna skulptura ali spomenik danes pogosto predstavljata le nekoliko izrazitejši del ulične opreme in pravzaprav nekakšen finančni vložek v atraktivno okolje, ki bo graditeljem posredno prinesel dobiček.

Izvedbeno in formalno smo dokaj na istem. Na vprašanji, zakaj takšna izvedba in zakaj ta izvajalec, sta dovolj odgovora, prvič, zakaj pa ne, saj umetnost je danes lahko praktično karkoli, in drugič, delal je že drugod. In potem so naša mesta in primestna krožišča v kratkem času polna štorastih objektov in identičnih krmežljavih figur, pri katerih denimo po neki čudni logiki verjamemo, da kombinacija realizma in grobe izmaličenosti delov skulptur pomeni kvalitetno sodobno umetnost. Tej »odprtosti« je v oporo še razumevanje umetnika kot zmožnega vsako (tudi sporno) vsebino ustrezno izraziti in pozitivno prekvasiti - in že imamo situacijo, kjer tako rekoč ni mogoče ustreliti mimo, kaj šele povzročiti škode. ${ }^{4}$

Takšen »dobrodušen « princip postavljanja javnih skulptur je toliko bolj problematičen, ko se uveljavlja tudi pri projektih na najvišji državni ravni ali pri zelo zahtevnih, politično ali kako drugače problematičnih projektih, ki bi potrebovali povsem drugačno obravnavo in pred gradnjo zelo temeljito pripravo. Primer zapleta, kjer neustrezno ravnanje različnih deležnikov v procesu nastajanja spomenika proizvede skrajno problematičen produkt, je SŽV, ki bo kmalu stal v središču Ljubljane. Med problematične deležnike štejem tudi neodzivnost širše javnosti, ki je zavladala nekje od razpisa natečaja. Med samostojno objavljenimi odzivi po zaključenem natečaju je bil najopaznejši morda prav odziv ključne iniciatorke spomenika Spomenke Hribar, ki se je v Mladini zgrozila nad tem, kaj bo priklicala v življenje, in prosila za ponoven

4 Ker spomeniki nastajajo na stičišču zelo različnih interesov pogosto tudi zelo različnih družbenih skupin in posameznikov, je tudi njihova znanstvena obravnava zelo težavna. Morala bi prečiti običajno zamejitev znanstvenih področij. Dodatno jo ovirajo različne področno imanentne specifike, denimo na umetnostnozgodovinskem (in nasploh umetnostnem) področju zanikana ekonomija in z njo usklajena umetnostna mitologija. Ti zelo opredeljujeta načine razmišljanja in delovanja vseh umetnostnih protagonistov, kar pa naj bi tistim izven umetnostnega polja ostalo prikrito (Pierre Bourdieu, The Rules of Art: Genesis and Structure of the Literary Field (Cambridge: Polity Press, 1996), 166-69). Umetnostni zgodovinarji se tako naročenim spomenikom med drugim radi izognemo prav zato, ker jih v skladu s trenutno operativno umetnostno mitologijo in njenim osredotočenjem na umetniško avtonomijo kot pogojem za doseganje »prave « umetnosti radi dojemamo manj kot umetnost in bolj kot utilitarne naloge, pri katerih se umetniki lahko pristno izrazijo le pogojno. Poglobljena analiza takšnih del ali njihovo poudarjanje v preglednih analizah opusov ustvarjalcev se zato pogosto zdita nepotrebni, če ne celo nezaželeni, saj v umetnostno razpravo vnašata nepriljubljen govor o politiki in ekonomiji ter nas soočata $\mathrm{z}$ dejstvom, da umetnik pogosto prav na področju javne plastike - ker gre za finančno dobro prekrvavljeno polje, ki prinaša medijsko pozornost, veliko simbolnega kapitala, možnost izvedbe velikih projektov v javnem prostoru in podobno - zavestno odstopa od avtonomije in se usklajuje s pričakovanji naročnikov, tudi z njihovo politično agendo.

Dejstvi, da ustvarjalce pri takšnih naročilih omejuje od naročnikov že vzpostavljen okvir projekta in jih lahko vanje vodijo (predvsem) praktični interesi, sta torej v bistvenem neskladju s splošnimi pričakovanji, da bo umetnik, v skladu s svojim statusom, pri njih sodeloval avtonomno, moralno in družbeno odgovorno ter zato, ker se s projektom identificira. Pomemben aspekt umetniškega statusa je uveljavljeno mnenje, da umetnik ne dela stvari, v katere ne verjame. Ker ga vidimo kot takega, že s svojim sodelovanjem v projektih te legitimira.

Sicer različna poklicna profila, likovni umetnik in arhitekt, sta $\mathrm{v}$ relaciji do spomenikov dojeta identično, $\mathrm{v}$ okviru zgoraj opisanega umetniškega statusa. 
premislek. ${ }^{5}$ Skrbno in smotrno je projekt obravnavalo nekaj ustvarjalcev iz arhitekturnih in oblikovalskih krogov. Dokaj glasni so bili v tej fazi tudi kiparji, a so prvenstveno negodovali nad tem, da se je na natečaj lahko prijavil le arhitekt, ki je tudi član Zbornice za arhitekturo in prostor Slovenije (oziroma vsak, ki si je našel takega arhitekta za prijavitelja), in se jih premalo upošteva. ${ }^{6}$

Premalo je bilo govora o odgovornosti za vsebino, učinkovanje spomenika; kako konkretno bo organiziral naš skupni prostor in o čem pravzaprav s svojo konkretno formo govori. Kot da se ne bi zares želeli zavedati, da s spomeniki ne razveseljujemo le turistov ali urejamo prostora, temveč tudi dejansko govorimo. Predvsem sebi in o sebi. In to ne o čemerkoli, temveč o pomembnih stvareh. O svojih vrednotah, svojih pogledih na svet. $Z$ njihovo pomočjo organiziramo in vizualiziramo tudi svoj spomin in svojo pozabo in trenutno ju prav s SŽV aktivno vpisujemo v javni prostor. Če ne bi bilo tako in spomeniki ne bi imeli močnega učinkovanja, jih tudi ne bi tako obsesivno rušili. In knjiga o ljubljanskih javnih spomenikih Božidarja Jezernika ne bi nosila povednega imena: Mesto brez spomina. ${ }^{7}$

5 Spomenka Hribar, »Spomini, ki družijo, spomini, ki ločujejo,« Mladina, 21. 8. 2015, pridobljeno 11. 2. 2020, https://www.mladina.si/168812/spomini-ki-druzijo-spomini-ki-locujejo/. Spomenka Hribar pri SŽV zelo lucidno prebere njegovo potencialno negativno učinkovanje, medtem ko sicer spomenike pogosto predstavlja kot nekakšne lakmusove papirje, ki le merijo že obstoječo polarizacijo v družbi.

Naše razmerje do spomenikov se zdi zaskrbljujoče podobno tistemu, ki ga poznamo iz poznega 19. stoletja, ko je spomenik že učinkovito polariziral našo skupnost navznoter in ko je pri nas produkcija meščanskih spomenikov zaradi naraščajočega nacionalizma (slovenskega, nemškega, italijanskega) vzcvetela dobesedno iz nič. Spomeniki znamenitim možem so se namreč razbohotili tudi zaradi nacionalističnih markiranj prostora prebivalcev naših krajev, ki so želeli s takšnimi gestami poudariti svojo prisotnost, pomen in tudi (več)vrednost do drugih skupin; skoznje se je sprožala živahna in pogosto tudi bojevita izmenjava (medijski diskurz, množične akcije in dogodki, pretepanje spomenikov in ob spomenikih, vandalizem in podobno). Spomenik v takšnem okolju je sicer seveda res slavil izbranega slavljenca, a še bolj je predstavljal in poosebljal skupnost, ki ga je postavila, in ji omogočal dovoljeno dolgotrajno sprožanje napetosti, agresivnega govora in dogajanja (ki je od druge ali drugih skupnosti dobesedno zahtevalo povračilne udarce).

Omeniti velja, da je to »bojno stanje « ob koncu 19. stoletja sploh šele priklicalo slovensko likovno umetnost kot samostojen fenomen. Pri spomenikih se je to pokazalo denimo v zahtevah po nacionalni ustreznosti avtorjev spomenikov (tudi v natečajih), ne le upodobljencev, saj je očitno le takšno ujemanje lahko dalo ustrezne produkte. Ker uveljavljenih »slovenskih « kiparjev tedaj nismo imeli, so v Ljubljani prve večje meščanske spomenike zato v delo dobili praktično še študentje, ki so delovali - paradoksalno ali tudi ne - pod vplivom svojih dunajskih profesorjev, in ne v smeri nekega specifično slovenskega likovnega izraza. Takšen utilitaren odnos do umetnosti umetniško kvaliteto in umetnikovo avtonomnost seveda potiska globoko v drugi plan.

Spomeniki, povezani z vojnami (padlim, žrtvam, vojnim dogodkom, grozotam, junakom, zmagam in porazom), predstavljajo posebno spomeniško zvrst z razvejano tipologijo, ki na Slovenskem prosperira že več kot sto petdeset let. Ta zvrst spomenika je zelo dovzetna za politikantstvo, nacionalizem, agresijo, hkrati pa za »medicinsko terminologijo «, po kateri naj bi, prav nasprotno, takšen spomenik zdravil, celil in združeval. - Gl. Beti Žerovc, »Public Monuments on the Territory of Yugoslavia from the Late $19^{\text {th }}$ Century to 1941 , v : Sanja Horvatinčić in Beti Žerovc, ur., Memorial Production in Socialist Yugoslavia 1945-1990 (Berlin: Archive Books, 2020) [v pripravi].

6 Npr. Mirko Bratuša, »Ministrstvo za enake možnosti (del prispevka Prihaja neučakana lopata),« Dnevnik, 10. 9. 2013, 4. Resne težave $\mathrm{v}$ spomeniški sferi so $\mathrm{v}$ naših medijih pogosto prevpite $\mathrm{z}$ obrobnimi vprašanji, kot so ali upodobljenec spomenika sme biti še živ, ali je bistveno, da pri spomeniku sodeluje kipar, in podobno. Razmišljanje o nujni prisotnosti kiparja za kvaliteten spomenik je nesmiselno, še sploh ker imamo kvalitetno tradicijo postavljanja samostojnih arhitekturnih spomenikov (Plečnik, Ravnikar, Marko Mušič in drugi). Strinjam pa se, da je zamejevanje javnih natečajev za le določene profile ustvarjalcev napačno in bi kot prijavitelji morali biti dobrodošli ustvarjalci širokega spektra. $\mathrm{V}$ tujini se kot avtorji spomenikov pojavljajo zelo raznoliki profili, od intermedijskih umetnikov do koreografov in $\gg$ mešanih firm «, kot denimo v primeru načrtovanega nemškega Spomenika svobode in enotnosti v Berlinu.

7 Zdi se, da se predvsem zaradi pogostega vdora motečih zasebnih interesov v javni prostor o njem $\mathrm{v}$ medijih in stroki zadnjih nekaj let več razpravlja (na primer kritika ekstenzivnega oglaševanja ali objektov v krožiščih; npr. Tina 


\section{Nepremišljeni prvi koraki}

V Sloveniji se že dlje časa ureja grobišča povojnih pobojev, komemorira in obeležuje se tudi med- in povojne žrtve na strani sodelavcev z okupatorjem. Država Slovenija je zamolčanim žrtvam povojnih pobojev leta 2004 med drugim postavila zelo monumentalen spomeniški kompleks Spominski park Teharje, ki je eden največjih spomeniških kompleksov pri nas po drugi svetovni vojni nasploh. Vendar namesto da bi nadaljevali čim hitrejše pietetno urejanje grobišč, končno pa, po več kot sedemdesetih letih (!), ustavili trend postavljanja monumentalnih spomenikov, posvečenih žrtvam in dogodkom druge svetovne vojne, država zelo nepremišljeno nadaljuje tudi to. Namreč, tudi pri SŽV se žrtve med sodelavci okupatorja med vojno in povojnih pobojev spet zdijo v ospredju; zdijo se pomembnejši motiv za gradnjo spomenika kot recimo žrtve prve svetovne vojne, nedavne osamosvojitvene vojne in tudi kot druge žrtve druge svetovne vojne (partizani, deportiranci, civilne žrtve represalij in internacij v taborišča itd.).

Sama - in verjetno nisem edina - se s takšnim spomenikom zato ne strinjam oziroma imam do njega zelo ambivalenten odnos. Nikakor ne želim, da se opravičuje in zanika napake preteklega sistema, in strinjam se s tem, da se povojne poboje in mučenja obsodi in vključi v splošni govor o naši preteklosti. Zaradi mene lahko stoji tudi neki osrednji spomenik, ki spoštljivo in obzirno komemorira žrtve vseh vojn. A nikakor ne sme biti nič več kot to in ne sme napeljevati v izenačevanje sodelovanja $\mathrm{z}$ okupatorjem $\mathrm{z}$ bojem proti okupatorju ali v krivično enačenje socializma v Sloveniji s totalitarnim komunizmom pod egido Rusov. Iz zgornjega jasno sledi, da sem pričakovala, da bo projekt SŽV speljan skrajno previdno in premišljeno. A to se žal ni zgodilo.

Pred nekaj leti je projekt SŽV z zakonsko osnovo dobil zeleno luč za gradnjo. Poleg vsebine je bil dan tudi posvetitveni napis, verz Otona Župančiča Domovina je ena, nam vsem dodeljena, in eno življenje in ena smrt. Ker ga je pesnik napisal prav za Grobnico narodnih herojev in je torej izrecno posvečen le enemu segmentu žrtev, ki jih pokriva spomenik, borcem NOB, je takšen izbor že hud odklon od vzpostavljanja inkluzivnega spomenika za vse slovenske žrtve vseh vojn. Fokus spomenika se je začel pretirano utrjevati na drugi svetovni vojni. Nonšalantni revizionizem te geste, ki jo je moč brati, kot da smo vsi isti in naj pozabimo na preteklost, da bo že enkrat mir, pa je tako brez občutka in tudi krivičen do vseh strani, da dobesedno sili v čustvena razčiščevanja. Takšen izbor je sprožil negativen odziv javnosti in razplamtel nezaupanje v projekt na vseh straneh. ${ }^{8}$

Lesničar, »Kako in komu postavljamo spomenike, « Delo, 4. 8. 2017, pridobljeno 19. 1. 2019, https://www.delo.si/ sobotna/kako-in-komu-postavljamo-spomenike.html.). Kritičen članek o slovenski sodobni javni plastiki je pred kratkim prispeval Miloš Kosec, »Javni spomenik med monumentalizmom konsenza in vrinjanjem zasebnega, « Likovne besede 109 (2018): 4-8. Na podlagi prej analiziranega gradiva opozarja predvsem na skoraj popolno prekinitev umetniške komunikacije slovenskega prostora s svetovnim razvojem na področju sodobnih spomenikov, še posebej spomenikov kolektivnih travm.

8 Za podrobno razlago nastanka verza gl. Matej Župančič in Alenka Župančič, »Edo Mihevc in Oton Župančič. Nastanek in usoda pesmi Domovina je ena, Z Zbornik za umetnostno zgodovino n. v. 50 (2014): 221-31. Alenka in Matej Župančič sta rabi verza njunega deda na SŽV nasprotovala in proti temu tudi glasno protestirala (na primer pri predsedniku RS). Protestirala sta kot državljana, in ne kot vnuka oziroma dediča. Mateju Župančiču se zahvaljujem za ljubezniva pojasnila. 
Projektna skupina za postavitev SŽV, ki ji je predsedovala Spomenka Hribar, je nato za spomenik izbrala lokacijo v najožjem središču Ljubljane, v neposredni bližini Parka Zvezde. Ta je verjetno ena najbolj elitnih in zaželenih v Sloveniji nasploh, a za ta spomenik še zdaleč ne najboljša. Njeno elitnost in zaželenost dokazuje dejstvo, da vsak, ki ima pri nas resno politično moč in si želi močne ideološke inskripcije v prostor, sili tja. Prvi v nizu te vrste spomenikov je bil tam leta 1860 postavljen spomenik znamenitemu avstrijskemu feldmaršalu in priljubljenemu častnemu meščanu Ljubljane Jozefu grofu Radeckemu, nedolgo zatem je tam stal imeniten konjeniški spomenik jugoslovanskega kralja Aleksandra. Oba sta bila kmalu odstranjena, spomenik kralju je bil uničen manj kot leto dni po nastanku. Megalomanska Fontana argonavtov, ki so jo tam načrtovali Italijani, je obtičala tik pred izvedbo, ker je Italija leta 1943 kapitulirala.

Glede na dejstvo, da tam ne zdrži dolgo ničesar političnega, bi bilo za spomenik s šibkim konsenzom javnosti in glede na to, da je bila bistvena želja iniciatorjev spoštljivo komemoriranje, povsem logično iskati lokacijo drugje in tudi povsem drugačne vrste. Sama bi iskala lokacijo, ki bi bila manj obremenjena z urbanističnimi problemi in ki bi bila tudi bolj umaknjena od mestnega vrveža. Prav tako bi iskala lokacijo, ki je bolj oddaljena od Trga republike in osrednjega spomenika revoluciji, da bi se izognili negativnemu sovplivanju spomenikov. Še zlasti pa ne bi gradila takšnega spomenika dobesedno na dvorišču Kazine, ki je bila v zadnjih desetletjih pred prvo svetovno vojno center konservativnega nemštva v Ljubljani. ${ }^{9}$ Med tem in slovenskim sodelovanjem z Nemci med drugo svetovno vojno seveda ni nobene prave povezave, a seštevanje pomenskih objektov v simbolni krajini je skrajno nepredvidljivo (sploh v vročekrvnih glavah).

\section{Neposrečeno pripravljen natečaj}

V izvedbenih fazah so se stvari zapletale naprej. Menim, da so različni akterji v projekt vstopali $\mathrm{z}$ dvomom in $\mathrm{z}$ vedno večjim nelagodjem. Namesto da bi problematizirali spomenik ali že dane smernice, so se osredotočali na formalne vidike gradnje, od vsebine pa so se distancirali.

Zgodba se tako nadaljuje $\mathrm{z}$ neposrečeno pripravljenim anonimnim natečajem, ki ga je leta 2013 razpisalo ministrstvo za delo, družino, socialne zadeve in enake možnosti skupaj z zbornico za arhitekturo in prostor (odslej ZAPS). Verjetno v zagati, kako sploh ravnati s takšno zahtevno problematiko, so razpisali natečaj, ki se je prvenstveno ukvarjal z regulacijo Južnega trga, nekako hkrati pa imel tudi nalogo, da vzpostavi spomenik in princip komemoriranja žrtev vseh vojn. V natečaju je bila v zvezi z vsebinskim delom te naloge le kratka, prazna razlaga, ki je povedala, čemu je spomenik posvečen,

9 Za razvoj trga in dogajanje na njem skozi zgodovino gl. Barbara Žabota, Kongresni trg: Zgodovina prostora do razpada Avstro-Ogrske (Ljubljana: Založba ZRC, 2011). Pred Kazino se je prva večja protinemška manifestacija zgodila prav zaradi spomenika! Šlo je za spomenik pesniku in politiku Antonu Aleksandru Auerspergu, ki so ga odkrili 3. 6. 1886 pred palačo Auerspergovih pri križevniški cerkvi (Žabota, Kongresni trg, 39). 
predložila obvezni napis in prepovedala ali omejila določeno eksplicitno simboliko in besedila. $\mathrm{V}$ vidnem nasprotju s tem so bili drugi, zlasti praktični, arhitekturni in urbanistični vidiki ter napotki predstavljeni zelo natančno. ${ }^{10}$

Kako bodo ravnali s takšno težavno vsebino, je bilo tako prepuščeno arhitektom. Razpisovalci so se morda zanašali na trenutno delujočo mitologijo o umetniku kot mediju, ki pretanjeno zazna zahtevno družbeno problematiko - recimo boleč odnos skupnosti do težavne, vendar za sedanjost in njeno samopotrditveno identiteto pomembne preteklosti - in jo zna pravilno prenestiv pozitivno učinkujoče umetniško delo. Verjetno so se zanašali tudi na preudarno ocenjevalno komisijo, ki bo znala pri prispelih projektih odbrati seme od plev in poiskati najboljšo možno rešitev.

$\mathrm{Na}$ natečaj je prispelo enainštirideset elaboratov. Prijaviteljev dane smernice in šibko oblikovani natečaj očitno niso motili. Oziroma nekatere so - vsaj po mojih poizvedovanjih -, vendar arhitekt menda mora, sploh $\mathrm{v}$ času krize, ravnati pragmatično in pri takšnih projektih sodelovati tako zaradi zaslužka kot zaradi reference, ki bo koristna za naprej. Kar pogosto sem lahko slišala tudi razmislek, da ob dejstvu, da se spomenik zagotovo bo gradil, je še vedno bolje, da se gradi kvaliteten kot slab projekt. ${ }^{11}$

Elaborate je nato dobila v roke komisija in polemizirala o njih na več sejah. Po razglasitvi rezultatov je bil natečaj predstavljen tudi z razstavo. Številni smo bili z razpletanjem projekta ali izborom sicer nezadovoljni, a negodovanja je bilo premalo, da bi to ustavljalo postopek. (Pre)malo ugovorov je bilo tudi z vidika kulturne dediščine. Park Zvezda in Kongresni trg doživljata postavljanje monumentalnih spomenikov skoraj, odkar obstajata, vendar jim je uspelo ohraniti avtentičen spomin na prvo polovico 19. stoletja, ko sta nastala. S SŽV bo spomin bistveno šibkejši, saj bo celota dobila povsem drugačen poudarek in novo težišče. ${ }^{12}$

10 Gradivo, povezano z natečajem, je dostopno na spletni strani ZAPS: »Spomenik žrtvam vseh vojn, Z Zbornica $z a$ arhitekturo in prostor Slovenije, pridobljeno 19. 1. 2019, https://www.zaps.si/index.php?m_id=natecaji_ izvedeni\&nat_id=119.

11 Natečajno nalogo je izdelal arhitekturni biro Ravnikar Potokar. Robert Potokar je, $v$ telefonskem pogovoru februarja 2017, moje pomisleke o prešibki razlagi vsebine in kontekstualizaciji projekta zavrnil z utemeljitvijo, da ustvarjalca ni treba omejevati s preveč vsebine, temveč mu je treba pustiti, da se samostojno izrazi.

Ustvarjalci vidno nihajo med nobilitacijo lastne pozicije, kjer si pripisujejo vse mogoče sposobnosti in kvalitete, in popolnim pragmatizmom, ki je v odnosu do spomenikov denimo viden tudi v tem, da so prav oni tisti, ki jih ne spoštujejo kot avtorska dela in so predlagatelji sprememb že obstoječih spomenikov (za SŽV gl. Janez Suhadolc, »Kamnita roka, ki z vso močjo objema rezilo meča, « Delo, 17. 11.2018, pridobljeno 19. 1.2019, https://www.delo. si/sobotna-priloga/kamnita-roka-ki-z-vso-mocjo-objema-rezilo-meca-111795.html.) ali so pripravljeni neposredno na spomenike umeščati logotipe naročnikov (npr. logotip Mladinske knjige na Pahorjevem spomeniku Mirsada Begića). Redkokdo problematizira »renegatstvo « avtorjev, ki so prešli od izdelovanja spomenikov NOB in revoluciji na domobranske spomenike, kamor lahko štejemo tudi avtorja osrednjega slovenskega spomenika revoluciji Draga Tršarja. Da takšno ravnanje vseeno ni sprejeto kot povsem nedolžno, kažejo zgovorni izbrisi. Recimo v monografiji o Mušičevem Parku spomina Teharje ni razlage, da je Mušič avtor vrhunskih spominskih kompleksov v SFRJ, kar je toliko bolj nenavadno, ker je teharski spomenik jugoslovanskim spomenikom NOB in revolucije tipološko zelo soroden (Edvard Kovač, Park spomina Teharje (Ljubljana: Založba ZRC in Atelje Marko Mušič, 2011)).

12 Članek Marka Zajca o SŽV ob hkratnem podajanju historiata spomenika poskuša razjasniti pojmovni okvir spomenika in ustroj, ki tega vzpostavlja. Med drugim pojasnjuje pojem sprave in kako se je zahtevi po spravi pri nas od zahteve ozke skupine razumnikov in kljub nestrinjanju ali celo ostremu nasprotovanju drugih razumnikov uspelo v javnosti uveljaviti kot nekakšna družbena nujnost. Dalje obravnava, kako se je s tem v zvezi vzpostavil odnos do preteklosti $s$ terapevtskim značajem, ki izrablja terminologijo s področja medicine in zdravja ter narekuje zdravljenje družbene realnosti tudi skozi prakse, kakršne so postavljanja spomenikov (Marko Zajc, »Spomenik Pr' Skelet in Zvezdi: k politiki spomina v Sloveniji v drugem desetletju tretjega tisočletja,« Prispevki za novejšo zgodovino, 60, št. 1 (2020). 


\section{Pomisleki o izbranem projektu}

Glede izbora komisije (v sestavi: predsednik arhitekt Aleksander Ostan, namestnik predsednika arhitekt Robert Potokar, umetnostna zgodovinarka Martina Vovk, arhitekt Janez Koželj in kipar Mirsad Begić; namestnici članov arhitektki Mojca Gregorski in Meta Hočevar) imam številne pomisleke.

Kot najboljšo rešitev je izbrala projekt skupine mlajših avtorjev pod vodstvom arhitekta Roka Žnidaršiča, ki je bil predložen pod šifro 51316. Nenavadna poteza zmagovalca je, da do natečaja ni naredil še nobenega spomenika. Prepoznavnejši del njegovega opusa so bila urejanja nabrežij, ulic in podobno, pri čemer je večkrat sodeloval z Mestno občino Ljubljana. Torej, nekdo, ki je dotlej delal predvsem praktične, uporabne stvari, je s SŽV nenadoma postal ključni kreator simbolne vsebine, in to skrajno težavne, in to pri ključnem spomeniku, ki se bo gradil pri nas v zadnjih letih, če ne desetletjih. Ob tem, da naročnik ni podal nobene vizije za spomenik in je bilo vse stavljeno na umetnika in moč umetnosti, se lahko vprašamo, kako da ni ne komisije, predvsem pa ne naročnika zaskrbelo, ali bo avtor brez izkušenj zares dorasel dani nalogi?

Seveda lahko rečemo, da komisija ni izbirala arhitekta, temveč projekt, kjer pa si je še manj moč zamisliti, kaj jo je prepričalo, da je ustrezen prav izbrani projekt. Kot prvo, vsebinsko grobo krši dodeljeni mandat. Iniciatorka spomenika Spomenka Hribar piše, da je spomenik vsebinsko neustrezen, ker je: » ... sestavljen iz dveh plošč,

Ob Zajčevi analizi vloge politike in medijev v tem procesu je lažje vzporedno misliti tudi to, kako umetnostno polje kot celota tem nekonsenzualnim vsebinam pritrjuje ali jih podpre. Ne le s tem, da - čeprav ni strokovno utemeljenega konsenza o tem, da spomeniki dejansko delujejo zdravilno na travmatizirane in postkonfliktne družbe, kot tudi ni konsenza o tem, da mi v tem trenutku smo takšna družba, in posledično o nujnosti sprave, kaj šele o tem, kaj naj bi ta sprava dejansko pomenila in kaj naj bi bili njeni elementi - postavlja in postavi takšen veliki državni spomenik, temveč tudi z odzivi in odnosom, ki ga skozi soočanje s projektom pokaže, zavzame do njih. To ima toliko večji pomen, ker se umetnostno polje dojema kot polje z izrazito družbeno odgovornostjo, ki se bo ob prepoznavanju potencialno družbeno škodljivih vsebin in ravnanj kritično odzvalo.

Pri SŽV je potrjevanje nekonsenzualnih revizionističnih vsebin verjetno steklo že z množičnim »privoljenjem« umetnostnega polja v sodelovanje, tako strokovnih sodelavcev (npr. članov komisije) kot sodelujočih umetnikov, saj se je v javnosti v zvezi s spomenikom sicer ves čas operiralo s pojmi razdvojenosti in sprave, ne glede na to, da se je natečajni poziv od tega ogradil. Nesporno pa se je utrdilo s tem, ko ni prišlo do ostrejšega problematiziranja revizionističnega značaja projekta, čeprav se je ta vse izraziteje kazal. Do večjega takega odziva - še zlasti bi se morali odzvati tisti, ki so projekt legitimirali s svojo udeležbo, a v veri, da sodelujejo pri spomeniku žrtvam vseh vojn, in ne pri spomeniku spravi - ni prišlo niti po tem, ko je leta 2015 izbrani projekt še dodatno neizpodbitno pokazal takšno usmeritev projekta; niti po tem, ko ga je tik po odkritju kot takšnega v članku v Sobotni prilogi Dela označil Aleksander Ostan, predsednik komisije, ki je obstoječo rešitev izbrala. Ostan smiselnost projekta, svojo vlogo in tudi izbrano rešitev utemeljuje prav skozi razcepljenost naroda, potrebo po spravi in procesu očiščenja. Pravi: $\gg$ To 'breme' sem vzel v zakup, saj sem hotel pomagati pri poskusu, da se rane razdvojenega naroda celijo tudi na ta način. ... Spomenik tudi ne more nadomestiti globinske sprave v narodu, ki jo lahko opravi le vsak posameznik sam pri sebi in z drugimi. Lahko pa predstavlja vsaj spodbudo in odprto znamenje, da je proces očiščenja potrebno storiti čim prej in čim bolj temeljito, da bodo lahko generacije, ki prihajajo, zadihale bolj prosto in neobremenjeno, sproščeno in povezano življenje.« (Aleksander Ostan, »Symballo (gr.): ponovno povezati, srečati in pridružiti se, « Delo, 14. 7.2017, pridobljeno 11.2.2020, https://www.delo.si/sobotna/symballo-gr-ponovno-povezati-srecati-in-pridruziti-se.html.).

Simptomatično, zlasti od odkritja dalje brez problematiziranja teče tudi opuščanje pravega imena spomenika, hkrati z večjim povezovanjem imena spomenika s pojmom sprave. Ostan v svojem članku Spomenik žrtvam vseh vojn imenuje Spomenik vsem žrtvam (SVŽ); vedno pogosteje je spomenik imenovan kar Spomenik spravi (Ostan, $\gg$ Symballo $\ll$ ). 
leve in desne, ki naj bi predstavljali našo narodno razdeljenost - kakor da bi šlo za spomenik izključno žrtvam, ki so povezane z drugo svetovno vojno! Gre pa za spomenik vsem žrtvam vseh naših vojn doslej, z žrtvami osamosvojitvene vojne vred. Bistvena napaka predloga tega spomenika je, da z mrtvimi, katerim naj bi bil posvečen, nima nobene zveze! Celo razlaga avtorjev zamisli spomenika je, da predstavlja našo razdeljenost. Kako so mrtvi med seboj 'razdeljeni', ne vemo. Dve ločeni plošči sta posnetek današnjega spora, torej je spor med živimi v tem spomeniku 'potegnjen' nazaj, v 'podzemlje', v spor med 'mrtvimi'. In ta spor naj bi bil v kamen vklesan, torej 'zabetoniran' za celo človeško večnost! « ${ }^{13}$ Predvidi, da bo takšen spomenik negativno učinkoval tudi v prihodnosti.

Torej spomenik vzpostavlja vsebino, ki ni bila razpisana in se, kjer je bil šibek konsenz, da se sploh komemorira žrtve vseh vojn, osredotoča na drugo svetovno vojno oziroma celo na naš današnji odnos do te problematike. Ne zanikam, da tovrstna polarizacija danes obstaja, vendar ta niti ni tema spomenika niti ni takšna, da bi potrebovala ali si celo zaslužila spomenik, še najmanj pa tako velikega. Naslednja težava namreč je, da arhitekt to neumestno vsebino po nepotrebnem še izdatno monumentalizira, in to povsem neustrezno. Na mestu spomina nas recimo ne bo pričakal neki konceptualen moment ali neko obeležje človeških dimenzij, temveč dva (!) ločena, skoraj dvajsetmetrska (!) betonska bloka iz peska in kamnov iz slovenskih rek in kamnolomov, ki bosta namenoma po obliki različna, po volumnu, masi in višini pa enaka! Skratka, spomenik, ki je dobesedno nasprotje tega, kar zapiše v razlagi svojega izbora komisija: $\gg$ Predlagana postavitev spomenika in njegova simbolna oblika sta izrazito nevtralni, brez nepotrebne patetike in $\mathrm{v}$ tem prostoru kot tudi času neprimerne monumentalnosti. ${ }^{14}$ Ker kaj, odsotnost figuralike že kar avtomatično pomeni nevtralnost in patetični ter času neprimerni so recimo makedonski neoklasicistični izlivi, minimalistično zdizajniran brušen beton pa to ne more biti? ${ }^{15}$

V Produkciji prostora piše, da so opozicije, »... ki stopajo v kod prostora, ki je konstruiran, da bi 'bil' pomenljiv in berljiv, nadvse splošne in preproste. Omejene so na kontraste med vodoravnicami in navpičnicami (prikrivajoč nadutost navpičnic). $\ll^{16}$ Vendar tudi brez Lefebvra je verjetno jasno, da je visoka navpična os poveden element. Navpičnica v evropski kulturi je običajno povezana z moškim principom in ta je prej kot spravljiv in združevalen dojet kot bojevit in tekmovalen, kar je lahko stopnjevano, če gre za dva, in to različna elementa. Bistven je še volumen navpičnic, tako v njunem medsebojnem razmerju kot $\mathrm{v}$ razmerju do volumna človeškega telesa, saj govori o njuni pomenski vrednosti in tudi o (straho)spoštovanju, ki ga moramo čutiti do

13 Hribar, »Spomini, ki družijo, spomini, ki ločujejo.«

14 Zaključno poročilo (Ljubljana: Ministrstvo za delo, družino, socialne zadeve in enake možnosti; Zbornica za arhitekturo in prostor Slovenije), 15, pridobljeno 19. 1.2019, https://www.zaps.si/system/download.php?dir=123\&file=I_ zakljucno+porocilo.pdf.

15 Za več o intenzivni in hitri produkciji novih spomenikov in objektov v historičnih slogih v okviru projekta Skopje 2014 kot poskusu konstruiranja nove makedonske identitete gl. Goran Janev, »Skopje 2014: Instrumentalizing Heritage for Unexpected Results, « v: Cultures of History Forum, 12. 4. 2015, pridobljeno 11. 2. 2020, DOI: 10.25626/0038.

16 Lefebvre, Produkcija prostora, 177. 
vsebine, ki jo podajata. Pomembno je, da se zavedamo, da se spomenik ne gleda le z očmi, temvečje fizično dejstvo, ki ga doživljamo s telesom. Ko smo soočeni z gibanjem okoli dveh krepkih blokov v desetkratni višini naših teles, nas ta prej kot k spravljivemu komemoriranju usmerjata k podrejanju in razporejanju.

Spomeniki - sploh tisti s šibkim konsenzom in udarno vsebino - lahko sprožajo nasilno ali žaljivo komemoriranje ter tudi nasilje nad spomenikom samim. Gre za splošno znana dejstva, ki se jih ob gradnjah poskuša upoštevati in tako minimizirati negativne učinke spomenikov. Sprašujem se, koliko je komisija - sicer je posebej pohvalila, kako lepo je domišljena pot uradne komemoracije - razmišljala o prispelih rešitvah s tega vidika? Katere nase dobesedno vlečejo vandalizem in negativne rituale in katere ne? Bodo ti kakorkoli prizadeli bližnja Spomenik revoluciji in Grobnico narodnih herojev? Se bodo člani komisije čudili, če se bodo na spomeniku znašli grafiti, le levo ali le desno? Ali torej obstaja možnost, da bo SŽV - kakršen bo in na tej lokaciji in s tem napisom - nasilje, ki je sicer na margini družbe, razpihoval in vlekel v njeno središče? Ko bo postavljen, bosta njegova raba in interpretacija namreč tekli po svoje, najsi si to graditelji želijo ali ne. Upam pa, da je razumljivo, da če spomenik izziva močno negativno performativnost, to ne pomeni, da je kvaliteten in učinkovit. ${ }^{17}$

\section{Interpretacija}

Kakorkoli že, spomenik bo očitno stal, in ker gre za osrednji državni spomenik, bo treba sebi, drugim, predvsem pa našim otrokom pojasnjevati njegov pomen. Treba bo razlagati, čemu se klanja naš predsednik, še sploh, ker to že po besedah samih avtorjev spomenika pač ni spomenik žrtvam vseh vojn!

Če si recimo zamislimo vodstvo tujcem, si verjetno lahko predstavljamo, da bomo vseeno najprej poskušali podtakniti izvorno vsebino, da s tem spomenikom komemoriramo žrtve vseh vojn - in potem bomo »zmrznili<, če bodo ljudje »naivno «, tako kot filozofinja Hribar, spraševali, čemu ta orjaška bloka in zakaj dva, če gre za žrtve vseh, torej več vojn? Ali morda mislimo le na prvo in drugo svetovno vojno? Smo izpustili osamosvojitveno vojno, čeprav smo jo doživeli? In potem bomo - kaj? Vsakič znova pojasnjevali, da je arhitekt monumentaliziral neko drugo vsebino, današnjo razklanost okrog druge svetovne vojne, jecljali o spravi in združenju v temeljih spomenika pod zemljo, na koncu pa z listka, ki ga bomo za te primere nosili s seboj, prebrali razlago, da sta $\gg . .$. postavitev spomenika in njegova simbolna oblika izrazito nevtralni, brez nepotrebne patetike in $\mathrm{v}$ tem prostoru kot tudi času neprimerne monumentalnosti $\ll_{.}{ }^{18}$

Karikiram in seveda, ne, ne bo tako. Spomenik je govor, ki je v skupnem prostoru in namenjen vsem in mora biti pojasnjen oziroma pojasnljiv temu primerno. Dolgotrajno

17 Iz natečajnega Zaključnega poročila in iz pogovorov s poročevalcem natečaja Luko Javornikom in članico komisije Martino Vovk sem razumela, da komisija o teh težavah sploh ni razpravljala. Odkar SŽV stoji, je bil večkrat vandaliziran, najpogosteje grafitiran.

18 Zaključno poročilo, 15. 
razpredanje je povsem neustrezno, in če ne daje jasnega sporočila s svojo formo in če še graditelji ne dajo jasnega impulza o vsebini, se pojasnilo vzpostavi samo! In tule lahko z dokajšnjo gotovostjo pričakujemo, kaj bo pojasnilo. Dvojnost, ki jo vsiljuje s svojo formo, utegne obveljati za sodelovanje z okupatorjem/nacifašizem in za NOB/SFRJ/ komunizem, pri čemer bo to posplošeno razumevanje ugodno podprlo danes mednarodno uveljavljeno enačenje dveh velikih političnih sistemov, čeprav ta s socializmom, ki smo ga živeli mi, nimata prav dosti. In ker imamo ljudje radi, da so stvari črno-bele in na prvi pogled razumljive, bo stvar opravljena. Zakaj bi vztrajali pri tem, da je bil naš sistem drugačen od skrajnih režimov na Vzhodu ali Zahodu in je vzpostavil številne svoboščine in pridobitve, ki še danes delajo naša življenja kvalitetna in lepa? Zakaj bi vztrajali pri naši izjemni zgodbi, če nam SŽV kot preverjena blagovna znamka, ki jo imajo v veliko kul svetovnih prestolnicah, že pove tisto, kar si najbolj želimo: isti smo kot oni. V svetu kapitalističnega enoumja brez alternativ je težko biti varuh drugačnega sporočila. Tako zelo, da počasi že sami dvomimo, da je bilo vse dobro, kar smo izkusili in vzpostavili v preteklem političnem sistemu, sploh resnično.

O tem, da je slovensko sodelovanje z okupatorjem pozitiven fenomen, da je zaveza okupatorju vrednota, v Sloveniji vsaj za zdaj ni konsenza, kaj šele, da bi obstajal konsenz, da se te fenomene glorificira na državni ravni. Težnje nekaterih po izenačevanju partizanskega boja s sodelovanjem z okupatorjem naletijo na težave na številnih ravneh. Med drugim je težko pozitivno vizualno podkrepiti takšen pogled. Kaj bi bile lahko podobe, ki bi sodelovanje z okupatorjem pozitivno ilustrirale? Kdo bi bil lahko navdihujoči obraz tistih, ki so se zavezali Italijanom ali Nemcem? Kaj bi bili lahko dogodki, ki bi jih slavili in bi nam predstavljali navdihujoča vodila v smislu, naj sledimo zgledu? Prisega Hitlerju na stadionu na njegov rojstni dan? Bitka, kjer je bil okupator v sodelovanju s Slovenci najuspešnejši v vojaških operacijah proti partizanski vojski? Bi bil morda toplo sprejet spomenik učinkovitemu mučenju tistih, ki so se borili proti okupatorju, recimo na Urhu? Kakorkoli obračamo, vsaj za zdaj je za večino Slovencev takšno podobje nesprejemljivo.

Manj težav pa ima normalizacija in nobilitacija sodelovanja z okupatorjem z vzpostavljanjem skozi abstraktne vizualne označevalce. Pri abstrakciji kavzalnost in dejstva lažje (u)tonejo v ozadje, blizu je občečloveškim stanjem. Tudi stoodstotnega branja in razumevanja abstraktnega govora ni, praktično vsaka interpretacija se lahko vselej odbije kot napačna. Zato recimo tudi težje dokazujemo, da je z abstraktnim spomenikom karkoli narobe, in posledično se manj ljudi spušča v takšne jalove bitke. Vendar vse to nam jasno pove, da izbira abstraktnega jezika še zdaleč ni nevtralna in tudi ne sme biti označena kot takšna. Prav takšna izbira omogoča, da stvari ostanejo nejasne in nedorečene, vendar pa to hkrati dopušča narekovanje vsebine od zunaj. ${ }^{19}$ Zato se moramo jasno zavedati, da abstrakcijo lahko bistveno opredeljujejo kontekst, razni

19 Vir za razumevanje političnosti abstrakcije je lahko že citrano Lefebvrovo delo. Danes morda najbolj znan primer specifične konkretne politične izrabe abstraktne umetnosti je podpora ameriške vlade abstraktnim tokovom po drugi svetovni vojni, kot demonstraciji, kako kapitalizem goji in vzpodbuja umetniško svobodo in svobodno izražanje: gl. npr. Frances Stonor Saunders, The Cultural Cold War: The CIA and the World of Arts and Letters (London in New York: New Press, 2000). 
vsebinski dodatki in podobno. SŽV je na začetku morda še imel vsaj potencialno možnost, da postane pozitivni pomnik $\mathrm{v}$ družbi, a je $\mathrm{z}$ izborom problematičnega napisa in lokacije že drsel $\mathrm{v}$ napačno smer. To bi morda lahko pozitivno še rešil neki zares mojstrski umetniški poseg, a kombinacija hkratne različnosti in enakosti dveh predimenzioniranih betonskih blokov le utrjuje že napeljani narativ. ${ }^{20}$

\section{Sodelavci}

Težava sodobne slovenske družbe ni v tem, da ne bi dovolj obžalovali povojnih pobojev in razumeli ali vsaj poskušali razumeti odločitev sodelavcev z okupatorjem. Mislim, da smo vse to ustrezno absolvirali. Težava je prej v tem, da tudi ko se jeziček na tehtnici vrednot želi premakniti dlje od tega in se boj proti okupatorju enači s sodelovanjem z okupatorjem ali se slednje celo tolmači kot bolj prav ali se pozablja na dobre plati naše bivše države, to nekako neradi in prepozno zaznamo. $V$ takšnih procesih celo sodelujemo, čeprav v to intimno ne verjamemo in mislimo, da je narobe, če tako ravnamo.

V seminar o spomenikih, povezanih $\mathrm{z}$ drugo svetovno vojno, ki sem ga vodila na Filozofski fakulteti preteklo leto, sem zato želela vključiti poglede udeležencev natečaja za SŽV na to, čemu so kot ustvarjalci zavezani in kako vidijo svojo vlogo v odnosu do tega spomenika. Spraševala sem jih med drugim: Ste imeli kakršnekoli pomisleke glede sodelovanja pri takšnem spomeniku? Kakšne? Ali intimno verjamete, da v središču Ljubljane potrebujemo takšen spomenik? Je to sploh pomembno? Ali verjamete, da bo tak spomenik pripomogel h kvalitetnejšemu življenju družbe?

Ker sem vselej izzvala izrecno nelagodje, sem kmalu prenehala. Čeprav so sogovorniki znali biti zelo pragmatični, tudi v smislu, da jih vsebina niti ne zadeva in je SŽV predvsem arhitekturna naloga, ista kot katerakoli druga, je bil za dobršen del vprašanih očitno spomenik pereč problem. In to morda predvsem v tem, kako narediti nekaj, da bo fizično izpadlo monumentalno in čim bolj vrhunsko, a bo hkrati tudi nekako nevidno, prazno in brez posebnosti in jih bo tako čim manj kompromitiralo kot sodelujoče $v$ projektu, ki se jim intimno zdi problematičen ali vsaj nepotreben.

Morda se je v tej neugodni »pasti« znašel tudi arhitekt Žnidaršič s svojo skupino in se iz nje poskušal izmotati z umikom iz etično obremenjujoče preteklosti $\mathrm{v}$ sodobnost. Tako namreč prideš do lahkotnejše dvojnosti, saj je cufanje okrog teh tem danes res praktično enako banalno na obeh straneh. In potem je lahko premišljeval o

20 SŽV lahko interpretiramo tudi skozi tipologijo, ki sta jo Breda in Oto Luthar vzpostavila za analizo domobranskih spomenikov (z majhnimi modifikacijami, recimo, da mešanje imen partizanskih in domobranskih borcev na spomenikih pri oziroma v SŽV nadomestijo premešani kamenčki vseh slovenskih rek). Lutharja sta med temeljnimi revizionističnimi koncepti, ki se uveljavljajo skozi domobranske spomenike, identificirala koncept sprave, ki z relativizacijo kolaboracije s fašizmom razprši krivdo in premesti vloge storilcev in žrtev in reinterpretacijo odporniškega gibanja in kolaboracije v skupni pojem bratomorne vojne (Breda Luthar in Oto Luthar, »Kolonizacija spomina, Politika in kontekstualnost domobranskih spomenikov po letu 1991, « v: Oto Luthar in Jurij Perovšek, ur., Zbornik Janka Pleterskega (Ljubljana: Založba ZRC, 2003): 659). 
Plečniku in Ravnikarju in drugih svetlih zgledih, izračunaval volumne ... in zasnoval spomenik, ki bo morda izpadel povsem čeden - a bo lahko tudi lepo služil kot vizualna opora neupravičenemu revizionizmu in nadaljnji delitvi duhov.

\section{$* * *$}

Problematičen spomenik torej ne bo zgrajen zaradi neupravičenih revizionističnih zahtev iniciatorjev spomenika, temveč zaradi neznanja na področju produkcije spomenikov in kanca oportunizma politikov, kanca oportunizma birokratov, kanca oportunizma umetnikov ... Mislim, da je večina vpletenih v projekt SŽV že davno čutila, da stvari ne grejo v pravo smer, a težko se »iztiriš«, če si »kolesce « v povsem legalnem sistemu in če se lahko tolažiš, da se bo odgovornost, za kakršnekoli očitke pač že, neboleče razporedila na veliko vpletenih.

Tudi na civilno družbo, ki ni rekla skoraj nič. Vsi delamo v predvidljivih, predpisanih orbitah in veliko razpravljamo na splošno, ob konkretnih problemih pa se pritajimo. Kako recimo sicer sploh razložiti, da imamo v Sloveniji izjemen porast umetnostnih protagonistov in institucij $\mathrm{v}$ zadnjih letih, hkrati pa bo eden osrednjih totemov našega plemena - poleg tega, da je formalno plitka rešitev - izkrivljal zgodovino in med drugim omalovaževal veliko junaštvo in žrtev plemena v preteklosti? Čemu smo sploh zavezani v umetnosti, če okrog tega ne rečemo nič? Tako radi tarnamo, da ni dovolj umetnostne kritike, a hkrati se obnašamo, kot da smo nad tem, da bi o spomeniku, ki bo zapičen v naše osrčje za vse in za vselej ${ }^{21}$ in za vsak dan, rekli kako besedo.

Morda je to eden od odgovorov na vprašanje, kako produkcijski način ureja in proizvaja svoj prostor in svoj čas in se na ta način dovrši. Ne le z nasiljem in samovoljo nekaterih, temveč tudi tako, da vsi odigramo predpisane vloge.

\section{Viri in literatura}

- $\gg$ Spomenik žrtvam vseh vojn.«Z Zbornica za arhitekturo in prostor Slovenije. Pridobljeno 19. 1. 2019. https://www.zaps.si/index.php?m_id=natecaji_izvedeni\&nat_id=119.

- Bourdieu, Pierre. The Rules of Art: Genesis and Structure of the Literary Field. Cambridge: Polity Press, 1996.

- Bratuša, Mirko. »Ministrstvo za enake možnosti.« Dnevnik, 10. 9. 2013.

- Hribar, Spomenka. »Spomini, ki družijo, spomini, ki ločujejo.« Mladina, 21. 8. 2015.

- Janev, Goran. »Skopje 2014: Instrumentalizing Heritage for Unexpected Results. « V: Cultures of History Forum, 12. 4. 2015, pridobljeno 11. 2. 2020, DOI: 10.25626/0038.

- Kosec, Miloš. »Javni spomenik med monumentalizmom konsenza in vrinjanjem zasebnega.« Likovne besede, 109 (2018): 4-8.

21 Misel, ki jo je Delo uporabilo kot naslov članka, ni izrečena (le) ironično, temveč kot opozorilo, da se spomenik lahko izruva ali »stoje« zdrkne v pozabo, poškodbe skupnosti, povzročene skozi soočenja okoli spomenika, pa ostanejo. Verjetno bomo enkrat prisiljeni tudi v razmislek o tem, kaj pomeni za nas kot skupnost ustoličeno pravilo, da je sodelovanje z okupatorjem sprejemljivo in pravilno. 
- Kovač, Edvard. Park spomina Teharje. Ljubljana: Založba ZRC, 2011.

- Lefebvre, Henri. Produkcija prostora. Ljubljana: Studia Humanitatis, 2013.

- Lesničar, Tina. »Kako in komu postavljamo spomenike.«Delo, 4. 8. 2017.

- Luthar, Breda in Oto Luthar. »Kolonizacija spomina: Politika in kontekstualnost domobranskih spomenikov po letu 1991.« V: Oto Luthar in Jurij Perovšek, ur. Zbornik Janka Pleterskega, 647-64. Ljubljana: Založba ZRC, 2003.

- Ostan, Aleksander. »Symballo (gr.): ponovno povezati, srečati in pridružiti se.« Delo, 14. 7. 2017.

- Saunders, Francis Stonor. The Cultural Cold War: The CIA and the World of Arts and Letters. London in New York: New Press, 2000.

- Suhadolc, Janez. »Kamnita roka, ki z vso močjo objema rezilo meča.« Delo, 17. 11. 2018.

- Zajc, Marko, »Spomenik pri Skeletu in Zvezdi. K politiki spomina v Sloveniji v drugem desetletju tretjega tisočletja.«Prispevki za novejšo zgodovino, LX, št. 1 (2020).

- Zaključno poročilo. Ljubljana: Ministrstvo za delo, družino, socialne zadeve in enake možnosti in Zbornica za arhitekturo in prostor Slovenije. Pridobljeno 19. 1. 2019. https://www.zaps.si/ system/download.php?dir=123\&file=I_zakljucno+porocilo.pdf.

- Žabota, Barbara. Kongresni trg: Zgodovina prostora do razpada Avstro-Ogrske. Ljubljana: Založba ZRC, 2011.

- Žerovc, Beti. »Public Monuments on the Territory of Yugoslavia from the Late $19^{\text {th }}$ Century to 1941.« V: Sanja Horvatinčić in Beti Žerovc, ur. Memorial Production in Socialist Yugoslavia 19451990. Berlin: Archive Books, 2020. [v pripravi]

- Žerovc, Beti. »Spomenik, ki bo zapičen v naše osrčje za vselej.« Delo, 17. 3. 2017.

- Župančič, Matej in Alenka Župančič. »Edo Mihevc in Oton Župančič: Nastanek in usoda pesmi Domovina je ena.« Zbornik za umetnostno zgodovino n. v. 50 (2014): 221-31. 


\section{Beti Žerovc}

\section{THE MONUMENT TO THE VICTIMS OF ALL WARS AND THE ISSUES OF CONTEMPORARY PUBLIC SCULPTURES AND MONUMENTS IN SLOVENIA}

\section{SUMMARY}

The text discusses some of the contemporary issues involved in erecting public sculptures and monuments in Slovenia. It focuses on the Monument to the Victims of All Wars, unveiled in the centre of Ljubljana in the summer of 2017. The monument and the events surrounding it are presented as an example of a predicament in which the inappropriate behaviour of the different stakeholders in the long-term process of monument creation produces numerous social disagreements and ultimately results in a problematic monument.

The article identifies and analyses the most problematic points on the path to the creation of the monument. It explores - also with the help of Henry Lefebvre's book The Production of Space - how the monument organises our common space and what it communicates with its form. Furthermore, it problematises the historical revisionism regarding World War II, which manifests itself in the monument and through the processes associated with it. It examines how and why such a large state monument can be created regardless of the absence of a professional consensus that monuments actually have a therapeutic effect on traumatised and post-conflict societies. There is also no consensus that Slovenians are currently such a society at all. The monument is often referred to as a tribute to reconciliation, although there is also no consensus about the necessity for reconciliation, let alone about what such reconciliation may actually mean and what its elements should be.

The text concludes with a deliberation on the role of art and art protagonists in the establishment of the monument based on vague and problematic premises. 